\title{
ANALISIS RISIKO DAN PENCEGAHANNYA PADA PELAKSANAAN PROYEK PEMBANGUNAN GEDUNG BERTINGKAT TINGGI DARI SISI KONTRAKTOR
}

\author{
Bernardus Calvin', Johny Johan² \\ ${ }^{1}$ Program Studi Magister Teknik Sipil, Universitas Tarumanagara - Jakarta \\ Email: bernardus.calvin@gmail.com \\ ${ }^{2}$ Program Studi Magister Teknik Sipil, Universitas Tarumanagara - Jakarta \\ Email: johnyjohan@gmail.com
}

Masuk: 08-01-2020, revisi: 24-01-2020, diterima untuk diterbitkan: 24-01-2020

\begin{abstract}
ABSTRAK
Pertambahan jumlah penduduk setiap tahun semakin meningkat di daerah ibukota Jakarta tetapi tidak sebanding dengan keterbatasan lahan yang ada pada saat ini. Oleh karena itu, pembangunan secara vertikal atau gedung bertingkat merupakan salah satu solusi yang tepat untuk mengatasi permasalahan tersebut. Penelitian ini bertujuan untuk mengidentifikasi risiko-risiko dominan yang terdapat dalam pelaksanaan proyek pembangunan gedung bertingkat tinggi, mendapatkan pemecahan masalah dan memberikan rekomendasi atau kontrol yang tepat terhadap variabel risiko tersebut. Metode penelitian dilakukan dengan mendapatkan data-data literatur dari berbagai jurnal dan penelitian terdahulu, melakukan validasi variabel bersama dengan para pakar, menyebarkan kuesioner kepada para responden, selanjutnya data diolah dengan bantuan metode AHP (Analytical Hierarchy Process) untuk menentukan kepentingan prioritas dari atribut kinerja dan memberikan bobot penilaian terhadap skala parameter yang digunakan. Terdapat 9 kategori risiko dalam penelitian ini antara lain safety, health \& environment, critical material \& supply management, contractor quality, subcontractor \& vendor, engineering, project management, financial, human resource dan external yang di dalamnya terdiri dari 64 variabel risiko. Hasil dari analisis data didapatkan 21 variabel yang temasuk ke dalam kategori risiko tinggi. Dari 21 variabel tersebut, variabel risiko yang paling dominan adalah variabel perubahan desain dari owner. Tindakan pencegahan atau kontrol yang tepat terhadap variabel risiko ini dapat dilakukan oleh kontraktor dengan memberikan notifikasi kepada owner bahwa pekerjaan atas perubahan tersebut berpengaruh pada nilai biaya dan waktu proyek, kemudian prosesnya harus mengikuti kaidah-kaidah kontrak yang digunakan, maksud prosesnya adalah dari owner memberikan SI (site instruction) kepada kontraktor atas perubahan desain sampai disetujui sebagai VO (variation order) oleh owner.
\end{abstract}

Kata Kunci: AHP; Gedung Bertingkat Tinggi; Identifikasi Risiko; Managemen Risiko

\begin{abstract}
The increasing number of population is increasing every year in the capital city of Jakarta, but is not proportional to the limitations of existing land at this time. Therefore, vertical construction or high rise building is one of the right solutions to overcome these problems. This study aims to identify the dominant risks involved in implementing high-rise building construction projects, obtain problem solving and provide recommendations or appropriate control over these risk variables. The research method was carried out by obtaining literature data from various journals and previous research, validating variables together with experts, distributing questionnaires to the respondents, then the data was processed with the help of the AHP (Analytical Hierarchy Process) method to determine the priority interests of the performance attributes and gives the weight of the rating of the parameter scale used. There are 9 risk categories in this study including safety, health \& environment, critical material \& supply management, contractor quality, subcontractor \& vendor, engineering, project management, financial, human resources and external, which consists of 64 risk variables. The results of the data analysis found 21 variables included in the high risk category. Of the 21 variables, the most dominant risk variable is the design change variable from the owner. Preventive action or appropriate control of this risk variable can be done by the contractor by notifying the owner that the work of the change affects the cost and time of the project, then the process must follow the rules of the contract used, the purpose of the process is that the owner gives SI (site instruction) to the contractor for design changes until it is approved as a VO (variation order) by the owner.
\end{abstract}

Keywords: Analytical Hierarchy Process (AHP); High Rise Building; Risk Identification; Risk Management 


\section{PENDAHULUAN}

\section{Latar Belakang}

Pertambahnya jumlah penduduk setiap tahun semakin meningkat di daerah ibukota Jakarta. Dengan bertambahnya jumlah penduduk berarti memerlukan penambahan sarana yang nyaman dan memadai untuk melakukan aktivitas mereka, yakni untuk bekerja atau tempat tinggal. Akan tetapi terdapat kendala dalam memenuhi kebutuhan tesebut salah satunya adalah keterbatasan lahan yang ada dan tidak sebanding dengan pertumbuhan penduduk di Jakarta. Oleh karena itu, pembangunan gedung bertingkat merupakan salah satu solusi yang tepat untuk mengatasi permasalahan tersebut. Dalam dunia konstruksi terutama proyek gedung bertingkat memiliki tingkat risiko yang sangat tinggi. Hal ini didasari oleh besarnya bobot pekerjaan dan tingginya struktur yang akan dibangun (Yuliana dan Hidayat, 2017). Sedangkan menurut PMBOK (2013) bahwa salah satu risiko terbesar dalam suatu proyek adalah kurangnya perencanaan yang memadai dan bagian yang terpenting dalam suatu proyek adalah manajemen risiko. Dampak dari risiko tersebut dapat mempengaruhi produktifitas, kualitas dan anggaran biaya proyek. Hal tersebut tersebut disebabkan oleh besarnya bobot pekerjaan dan tingginya bangunan gedung yang akan dibangun dengan rentang waktu pelaksanaan yang terbatas (Zhou, dkk., 2014). Oleh sebab itu, dalam penelitian ini akan melakukan analisis risiko terhadap pelaksanaan proyek pembangunan gedung bertingkat tinggi dan mengetahui bagaimana pencegahannya yang tepat terhadap risiko - risiko yang bersifat dominan tersebut.

\section{Rumusan Masalah}

Dalam penelitian ini membahas beberapa rumusan masalah di dalamnya, antara lain adalah banyaknya kriteria potensial dari masing-masing risiko, risiko apa yang paling dominan, mengetahui hasil analisis risiko dan bagaimana pencegahannya terhadap pelaksanaan proyek pembangunan gedung bertingkat tinggi dan yang terakhir adalah rekomendasi perbaikan apa yang tepat dari hasil analisis tersebut yang berguna untuk proyek tersebut atau proyek-proyek yang akan datang.

\section{METODE PENELITIAN}

Metode dalam penelitian ini akan dilakukan dengan tiga tahapan proses penelitian yaitu tahap pengumpulan data, tahap analisis data dan tahap pembahasan dari hasil analisis data. Pada tahap pengumpulan data akan dilakukan kajian pustaka dari berbagai jurnal-jurnal penelitian dan buku yang relevan terkait manajemen risiko/ analisis risiko proyek konstruksi gedung bertingkat tinggi yang selanjutnya dijadikan sebagai data sekunder. Kemudian menggunakan metode wawancara dengan para pakar untuk memperoleh validasi, verifikasi dan klarifikasi terhadap variabelvariabel risiko yang dapat mempengaruhi kinerja pelaksanaan proyek konstruksi gedung bertingkat, membuat rancangan survey keusioner, menyebarkan kuesioner kepada responden. Untuk mendapatkan data primer yang dibutuhkan maka digunakan skala likert dalam penyebaran kuesioner tersebut, di mana para responden akan memberikan penilaian terhadap tingkat probabilitas terjadinya (likelihood) dan seberapa besar dampak (impact) dari variabel-variabel risiko yang telah divalidasi sebelumnya. Terdapat 5 skala likert yang digunakan dalam penilaian terhadap tingkat probabilitas terjadinya yaitu skala 1 artinya sangat jarang dan skala 5 artinya sangat sering, sedangkan untuk penilaian besarnya dampak terjadinya yaitu skala 1 artinya tidak berpengaruh dan skala 5 artinya sangat berpengaruh.

Selanjutnya pada tahap analisis data dilakukan dengan bantuan metode AHP (Analytical Hierarchy Process) untuk memperoleh pembobotan terhadap skala parameter frekuensi dan dampak sehingga dapat ditentukan peringkat masing-masing variabel risiko tersebut atau risiko 
mana saja yang dominan. Hasil dari analisis data ini dilanjutkan untuk dilakukan pembahasan kepada para pakar terkait risiko-risiko dominan tersebut untuk mengetahui kontrol atau pencegahan risiko yang tepat terhadap kinerja pelaksanaan proyek konstruksi gedung bertingkat.

\section{HASIL DAN PEMBAHASAN}

Pada penelitian ini terdapat 9 kategori risiko dalam pembangunan gedung bertingkat tinggi yang diperoleh dari hasil kajian pustaka dan telah divalidasi oleh 5 orang pakar yang antara lain yaitu safety, health and environment risk, critical material \& supply management risk, contractor quality risk, subcontractor \& vendor risk, engineering risk, project management risk, financial risk, human resource risk dan external risk yang di dalamnya terdiri dari 64 variabel risiko. Untuk lebih jelasnya dapat dilihat pada Tabel 1.

Tabel 1. Variabel Risiko dalam Pelaksanaan Proyek Pembangunan Gedung Bertingkat Tinggi

\begin{tabular}{|c|c|}
\hline Kodel Variabel & Variabel \\
\hline \multicolumn{2}{|c|}{ Safety, Health \& Environment Risk } \\
\hline $\mathbf{X 1}$ & $\begin{array}{l}\text { Kurangnya perencanaan (Metode Kerja) dan pengawasan atas implementasi perencanaan } \\
\text { pekerjaan terutama pada pekerjaan yang berisiko tinggi }\end{array}$ \\
\hline $\mathbf{X} 2$ & Pekerjaan tidak dilakukan sesuai prosedur K3 yang ditetapkan \\
\hline $\mathbf{X 3}$ & Subkon/pekerja melakukan pekerjaan tanpa adanya work permit \\
\hline $\mathbf{X 4}$ & Kurangnya tingkat kepedulian dan kesadaran pengawas, staf/pekerja terkait K3 \\
\hline $\mathbf{X 5}$ & Kurang memadainya fasilitas K3 pendukung di lapangan \\
\hline X6 & Terjadi kebakaran akibat dari limbah B3/Solar atau Bensin \\
\hline $\mathbf{X} 7$ & Kecelakaan akibat robohnya Climbing Formwork \\
\hline $\mathbf{X 8}$ & Terjadi material yang terjatuh dari ketinggian \\
\hline X9 & Kecelakaan kerja akibat pekerja jatuh dari ketinggian \\
\hline $\mathbf{X 1 0}$ & Kecelakaan kerja akibat tersengat aliran arus listrik/konsleting \\
\hline $\mathbf{X 1 1}$ & Kecelakaan kerja pada saat pekerjaan panas \\
\hline $\mathbf{X 1 2}$ & Kecelakaan kerja pada saat bekerja di ruangan terbatas \\
\hline $\mathbf{X 1 3}$ & Kecelakaan kerja pada saat proses pengangkatan (Lifting) \\
\hline X14 & Terjadinya Fatality di lokasi proyek \\
\hline \multicolumn{2}{|c|}{ Critical Material \& Supply Management Risk } \\
\hline $\mathbf{X 1 5}$ & Keterlambatan kedatangan material (Lokal atau Import) \\
\hline $\mathbf{X 1 6}$ & Pemakaian dan permintaan material yang berlebihan \\
\hline $\mathbf{X 1 7}$ & Perencanaan atau planning kebutuhan material yang tidak tepat \\
\hline $\mathbf{X 1 8}$ & Manajemen rebar yang buruk (Tingginya rebar waste) \\
\hline $\mathbf{X 1 9}$ & Kuantitas material yang dikirim tidak sesuai dengan pemesanan \\
\hline $\mathbf{X 2 0}$ & Keterbatasan gudang penyimpanan \\
\hline $\mathbf{X 2 1}$ & Kualitas material tidak sesuai spesifikasi \\
\hline $\mathrm{X} 22$ & Kerusakan material \\
\hline
\end{tabular}




\section{Contractor Quality Risk}

\begin{tabular}{ll}
\hline $\mathbf{X 2 3}$ & Kualitas bekisting (formwork) yang buruk \\
\hline $\mathbf{X 2 4}$ & Kualitas hasil pekerjaan yang buruk dan banyak pekerjaan perbaikan (rework) \\
\hline X25 & Penggunaan mutu material di bawah standar \\
\hline X26 & Terjadinya Checklist berulang kali \\
\hline $\mathbf{X 2 7}$ & Pekerjaan tidak menerapkan metode konstruksi yang disetujui \\
\hline $\mathbf{X 2 8}$ & Kondisi tools pendukung pengecoran yang buruk atau tidak dikalibrasi \\
\hline $\mathbf{X 2 9}$ & Kurangnya pemahaman terhadap standar mutu yang diminta konsumen/ owner \\
\hline $\mathbf{X 3 0}$ & Belum terbiasa dengan pengunaan teknologi alat baru
\end{tabular}

Subcontractor and Vendor Risk

\begin{tabular}{|c|c|}
\hline $\mathbf{X 3 1}$ & Komunikasi dan koordinasi yang kurang baik antara kontraktor utama dengan Subkontraktor \\
\hline $\mathbf{X 3 2}$ & Kurang tegasnya kontraktor utama dalam pemberian sanksi terhadap Subkontraktor \\
\hline X33 & Kurangnya inspeksi dari pihak kontraktor utama terkait performa subkontraktor \\
\hline X34 & Kurangnya pengalaman subkontraktor dalam menangani proyek sejenis \\
\hline X35 & Kurangnya produktivitas lapangan dari subkontraktor \\
\hline X36 & Keterlambatan pembayaran mandor/ vendor/ subkontraktor \\
\hline $\mathbf{X 3 7}$ & Kurangnya kemampuan/ skill tenaga kerja dari pihak subkontraktor \\
\hline X38 & Pemilihan subkontraktor yang kurang selektif \\
\hline \multicolumn{2}{|c|}{ Engineering Risk } \\
\hline X39 & Keterlambatan produksi shop drawing \\
\hline $\mathbf{X 4 0}$ & Distribusi shop drawing yang tidak merata sampai ke tim konstruksi \\
\hline $\mathbf{X 4 1}$ & Perubahan desain dari owner \\
\hline $\mathbf{X} 42$ & Pemahaman enjiner proyek terkait desain \\
\hline $\mathbf{X 4 3}$ & Pemilihan metode kerja yang tidak tepat \\
\hline
\end{tabular}

\section{Project Management Risk}

\begin{tabular}{|c|c|}
\hline $\mathbf{X 4 4}$ & Terjadinya kehilangan dokumen-dokumen proyek \\
\hline X45 & $\begin{array}{l}\text { Pekerjaan berhenti dalam jangka waktu lama akibat adanya pengetesan material/ beban (Untuk } \\
\text { kasus pondasi) }\end{array}$ \\
\hline X46 & Keterlambatan progress atau schedule pekerjaan \\
\hline $\mathbf{X} 47$ & Hubungan kerja yang tidak harmonis antara owner dan kontraktor \\
\hline X48 & Kurangnya pengarahan dari pimpinan proyek \\
\hline $\mathbf{X 4 9}$ & Tidak lengkapnya laporan harian \\
\hline \multicolumn{2}{|c|}{ Financial Risk } \\
\hline $\mathbf{X 5 0}$ & Kurangnya pendanaan untuk proyek \\
\hline X51 & Terjadinya perbedaan pengakuan cost antara kontraktor dengan owner \\
\hline X52 & Adanya denda keterlambatan dari owner \\
\hline X53 & Terjadi keterlambatan pembayaran dari owner \\
\hline X54 & Prosedur pengendalian biaya proyek kurang memadai (cash flow) \\
\hline
\end{tabular}




\begin{tabular}{cl}
\hline \multicolumn{1}{l}{ Human Resource Risk } \\
\hline X55 & Kurangnya koordinasi yang baik di dalam organisasi proyek \\
\hline X56 & Kepindahan (resign) pekerja senior yang potensial \\
\hline X57 & Kompetensi pekerja yang tidak memadai di lapangan \\
\hline X58 & Terjadinya pemogokan tenaga kerja \\
\hline X59 & Jumlah anggota staff tidak sesuai dengan kebutuhan proyek \\
\hline External Risk & \\
\hline X60 & Bencana alam (Banjir, gempa bumi, badai, angin kencang) \\
\hline X61 & Terorisme \\
\hline X62 & Terjadi huru-hara atau demo \\
\hline X63 & Pergantian pemerintahan yang berpengaruh terhadap kebijakan perdagangan dan moneter \\
\hline X64 & Kondisi pasar domestik lesu atau daya beli properti menurun \\
\hline
\end{tabular}

Data tabel tersebut kemudian dibuatkan ke dalam kuesioner yang akan disebarkan kepada 33 responden penelitian yang telah memiliki minimum pengalaman kerja 5 tahun di proyek pembangunan gedung bertingkat dan lebih diutamakan kepada level manajerial. Para responden penelitian akan memberikan penilaian terhadap frekuensi dan dampak dari setiap variabel risiko dengan menggunakan skala likert. Skala likert dapat dilihat pada tabel 2.

Tabel 2. Skala Likert Frekuensi dan Dampak

\begin{tabular}{ccc}
\hline Skala & Frekuensi & Dampak \\
\hline $\mathbf{5}$ & Sangat Sering & Sangat Berpengaruh \\
\hline $\mathbf{4}$ & Sering & Berpengaruh \\
\hline $\mathbf{3}$ & Sedang & Cukup Berpengaruh \\
\hline $\mathbf{2}$ & Jarang & Kurang Berpengaruh \\
\hline $\mathbf{1}$ & Sangat Jarang & Tidak Berpengaruh \\
\hline
\end{tabular}

Data primer yang berasal dari kuesioner kemudian diolah dengan menggunakan metode AHP (Analytical Hierarchy Process). Metode ini menggunakan perbandingan berpasangan dengan bantuan pakar untuk menentukan pentingnya kriteria dalam suatu keputusan (Saaty dan Tran, 2007). Dalam penelitian ini metode AHP digunakan untuk mendapatkan nilai pembobotan (nilai eigen) dari setiap skala parameter frekuensi dan dampak yang digunakan. Hasil nilai pembobotan dari analisa metode AHP dapat dilihat pada tabel 3.

Tabel 3. Nilai Pembobotan Skala Parameter Frekuensi dan Dampak

\begin{tabular}{cccccc}
\hline $\begin{array}{c}\text { Skala } \\
\text { Parameter }\end{array}$ & $\mathbf{1}$ & $\mathbf{2}$ & $\mathbf{3}$ & $\mathbf{4}$ & $\mathbf{5}$ \\
\hline Nilai Eigen & 0.5028 & 0.2602 & 0.1344 & 0.0678 & 0.0348 \\
\hline
\end{tabular}


Berdasarkan perhitungan pengujian rasio konsistensi (CR) hierarki, dengan indeks random (RI) sebesar 1,12 ( $\mathrm{n}=5)$, dihasilkan nilai rasio konsistensi sebesar 8,34\% atau lebih kecil dari 10\%, yang artinya konsistensi matriks terhadap hierarki skala parameter frekuensi dan dampak risiko dapat diterima.

Setelah diketahui nilai skala frekuensi (probability) dan dampak (impact) dari data primer kuesioner, maka dilanjutkan dengan menentukan tingkat risiko atau risk level dengan menggunakan tabel matriks Probability x Impact (P x I). Menurut Cortin (2014) bahwa tujuan dalam penilaian risiko adalah untuk mengevaluasi tingkat keparahan dari setiap risiko yang telah teridentifikasi. Untuk lebih jelasnya dapat dilihat seperti pada gambar 1 di bawah ini.

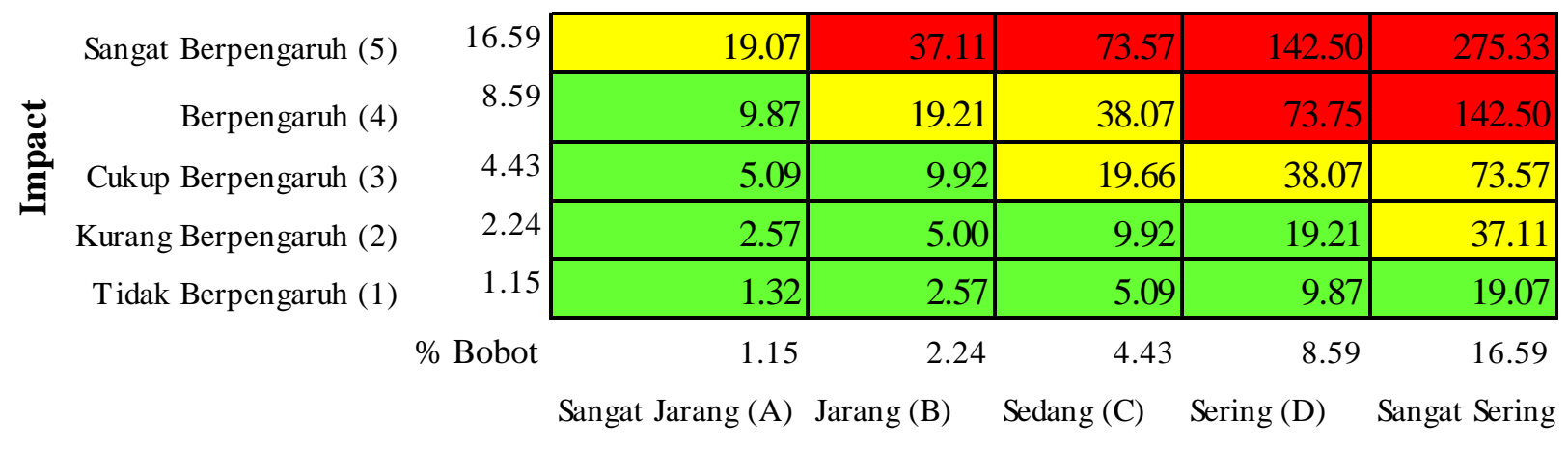

Likelihood

\section{\begin{tabular}{l|l|l|l} 
Low & Medium & High \\
\hline
\end{tabular}}

Gambar 1. Matriks Peta Risiko Dampak dan Frekuensi

Dari gambar 1 di atas menggambarkan klasifikasi risiko terdiri dari 3 (tiga) tingkatan yaitu high risk (merah), medium risk (kuning), low risk (hijau). Penempatan tingkat risiko berdasarkan kategori tinggi rendahnya pada matriks tersebut mengacu kepada PMBOK (2017), sedangkan angka persentase bobot tersebut berasal dari perhitungan AHP sebelumnya.

Setelah menentukan tingkat risiko dari matriks peta risiko di atas, maka dihasilkan 21 variabel risiko yang termasuk dalam kategori risiko tingkat tinggi (high risk) atau dominan pada pelaksanaan proyek pembangunan gedung bertingkat tinggi. Berikut rekapitulasi hasil variabel risiko dominan pada tabel 4 . 
Tabel 4. Variabel Risiko Dominan

\begin{tabular}{|c|c|c|c|c|}
\hline Kategori & & Variabel Risiko & $\begin{array}{l}\text { Nilai Faktor } \\
\text { Risiko }\end{array}$ & Level Risiko \\
\hline Engineering risk & $\mathrm{X} 41$ & Perubahan desain dari owner & 56.71 & High \\
\hline Contractor quality risk & $\mathrm{X} 24$ & $\begin{array}{l}\text { Kualitas hasil pekerjaan yang buruk dan banyak } \\
\text { pekerjaan perbaikan (rework) }\end{array}$ & 50.85 & High \\
\hline Financial risk & X53 & Terjadi keterlambatan pembayaran dari owner & 48.44 & High \\
\hline Project management risk & $\mathrm{X} 46$ & Keterlambatan progress atau schedule pekerjaan & 48.21 & High \\
\hline $\begin{array}{l}\text { Critical material \& supply } \\
\text { management risk }\end{array}$ & $\mathrm{X} 18$ & Manajemen rebar yang buruk (tingginya rebar waste) & 44.26 & High \\
\hline $\begin{array}{l}\text { Safety, health \& } \\
\text { environment risk }\end{array}$ & $\mathrm{X} 1$ & $\begin{array}{l}\text { Kurangnya perencanaan (metode kerja) dan pengawasan } \\
\text { atas implementasi perencanaan pekerjaan terutama pada } \\
\text { pekerjaan yang berisiko tinggi }\end{array}$ & 37.57 & High \\
\hline Engineering risk & X39 & Keterlambatan produksi shop drawing & 37.41 & High \\
\hline $\begin{array}{l}\text { Critical material \& supply } \\
\quad \text { management risk }\end{array}$ & $\mathrm{X} 15$ & Keterlambatan kedatangan material (lokal atau impor) & 36.14 & High \\
\hline Financial risk & X54 & $\begin{array}{l}\text { Prosedur pengendalian biaya proyek kurang memadai } \\
\text { (cash flow) }\end{array}$ & 35.75 & High \\
\hline Contractor quality risk & $\mathrm{X} 23$ & Kualitas bekisting (formwork) yang buruk & 35.51 & High \\
\hline Financial risk & X50 & Kurangnya pendanaan untuk proyek & 34.87 & High \\
\hline $\begin{array}{l}\text { Subcontractor \& vendor } \\
\text { risk }\end{array}$ & $\mathrm{X} 37$ & $\begin{array}{l}\text { Kurangnya kemampuan/ skill tenaga kerja dari pihak } \\
\text { subkontraktor }\end{array}$ & 33.56 & High \\
\hline $\begin{array}{l}\text { Safety, health \& } \\
\text { environment risk }\end{array}$ & $\mathrm{X} 8$ & Terjadi material yang terjatuh dari ketinggian & 33.51 & High \\
\hline Contractor quality risk & $\mathrm{X} 26$ & Terjadinya checklist berulang kali & 32.74 & High \\
\hline $\begin{array}{l}\text { Critical material \& supply } \\
\quad \text { management risk }\end{array}$ & $\mathrm{X} 17$ & $\begin{array}{l}\text { Perencanaan atau planning kebutuhan material yang } \\
\text { tidak tepat }\end{array}$ & 32.16 & High \\
\hline $\begin{array}{l}\text { Critical material \& supply } \\
\quad \text { management risk }\end{array}$ & $\mathrm{X} 16$ & Pemakaian dan permintaan material yang berlebihan & 31.73 & High \\
\hline $\begin{array}{l}\text { Safety, health \& } \\
\text { environment risk }\end{array}$ & $\mathrm{X} 2$ & $\begin{array}{l}\text { Pekerjaan tidak dilakukan sesuai prosedur K3 yang } \\
\text { ditetapkan }\end{array}$ & 31.60 & High \\
\hline $\begin{array}{l}\text { Subcontractor \& vendor } \\
\text { risk }\end{array}$ & $\mathrm{X} 35$ & Kurangnya produktivitas lapangan dari subkontraktor & 29.13 & High \\
\hline $\begin{array}{l}\text { Safety, health \& } \\
\text { environment risk }\end{array}$ & X9 & Kecelakaan kerja akibat pekerja jatuh dari ketinggian & 28.87 & High \\
\hline $\begin{array}{l}\text { Safety, health \& } \\
\text { environment risk }\end{array}$ & $\mathrm{X} 14$ & Terjadinya fatality di lokasi proyek & 25.50 & High \\
\hline $\begin{array}{l}\text { Safety, health \& } \\
\text { environment risk }\end{array}$ & $\mathrm{X} 7$ & Kecelakaan akibat robohnya climbing formwork & 24.73 & High \\
\hline
\end{tabular}

Untuk selanjutnya dilakukan pembahasan bersama dengan para pakar terkait variabel risiko dominan tersebut untuk membahas bagaimana tindakan kontrol atau pencegahan risiko yang tepat terhadap pelaksanaan proyek pembangunan bertingkat tinggi. Berikut dapat dilihat tindakan kontrol atau pencegahan risiko pada tabel 5. 


\section{Tabel 5 Tindakan Kontrol atau Pencegahan Risiko Terhadap Variabel Risiko Dominan}

\begin{tabular}{|c|c|c|}
\hline & Variabel Risiko & Kontrol/ Pencegahan Risiko \\
\hline X41 & Perubahan desain dari owner & $\begin{array}{l}\text { - Memastikan prosesnya harus mengikuti kaidah-kaidah kontrak yang } \\
\text { digunakan. (dari awal menerima instruksi kerja dari owner sampai } \\
\text { dipastikan instruksi kerja tersebut sebagai VO) } \\
\text { - Memberikan notifikasi kepada owner bahwa pekerjaan atas perubahan } \\
\text { tersebut berpengaruh kepada nilai biaya dan waktu. }\end{array}$ \\
\hline $\mathbf{X} 24$ & $\begin{array}{l}\text { Kualitas hasil pekerjaan yang } \\
\text { buruk dan banyak pekerjaan } \\
\text { perbaikan (rework) }\end{array}$ & $\begin{array}{l}\text { - Melakukan kualifikasi atau pemilihan terhadap tenaga kerja (supervise } \\
\text { dan pekerja) dan material yang berkualitas } \\
\text { - Memastikan metode kerja yang dilaksanakan sudah benar dan lengkap }\end{array}$ \\
\hline $\mathbf{X 5 3}$ & $\begin{array}{l}\text { Terjadi keterlambatan } \\
\text { pembayaran dari owner }\end{array}$ & $\begin{array}{l}\text { - Memastikan kemampuan keuangan owner pada saat melakukan tender } \\
\text { - Rutin dalam memantau progress dan pembayaran oleh pihak owner } \\
\text { - Memperdalam pemahaman atas kontrak yang digunakan terlebih perihal } \\
\text { pembayaran dari owner }\end{array}$ \\
\hline
\end{tabular}

X46 Keterlambatan progress atau - Melakukan perencanaan yang baik terhadap semua aspek, meliputi schedule pekerjaan jadwal pekerjaan, penyediaan material, alat dan tenaga kerja.

- Meningkatkan performa kualitas terhadap tim engineering dengan memberikan pelatihan-pelatihan dan berbagi pengetahuan (sharing knowledge) antara sesame rekan tim.

X18 Manajemen rebar yang buruk (tingginya rebar waste)

X1 Kurangnya perencanaan (metode kerja) dan pengawasan atas implementasi perencanaan pekerjaan terutama pada pekerjaan yang berisiko tinggi

X39 Keterlambatan produksi shop drawing
- Menyiapkan atau merekrut BBS engineer yang berkualitas

- Melakukan sistem kontrol atas fabrikasi pembesian yang lebih baik lagi

- Membuat metode kerja yang tepat untuk segala pekerjaan yang memiliki tingkat risiko yang tinggi

- Pengawasan terhadap pekerjaan dilakukan secara sistematis dan disiplin

- Meningkatkan kualitas dan kemampuan dari sumber daya manusia (SDM) akan keselamatan kerja yang memiliki tingkat risiko tinggi

- Memberikan maintenance atau perawatan secara berkala terhadap perangkat pendukung kerja

- Membuat planning terhadap kebutuhan gambar forcon yang dibutuhkan, sehingga kontraktor harus aktif melakukan notifikasi kepada pihak owner (Issued for Construction Drawing) untuk segera menyediakan gambar kerja forcon yang dibutuhkan oleh kontraktor dan memastikan gambar sudah sangat jelas untuk dibuat ke dalam gambar kerja (shop drawing) oleh kontraktor

- Meningkatkan performa kualitas terhadap tim engineering dengan memberikan pelatihan-pelatihan dan berbagi pengetahuan (sharing knowledge) antara sesame rekan tim

X15 Keterlambatan kedatangan - Memastikan persediaan material sesuai dengan yang dibutuhkan material (lokal atau impor)

- Melakukan persetujuan material lebih cepat dan pemesanan material lebih awal.

- Melakukan perencanaan terhadap kedatangan material yang layak

- Memberikan kejelasan spesifikasi kebutuhan material yang dibutuhkan

X54 Prosedur pengendalian biaya proyek kurang memadai (cash flow)

- Membuat perencanaan dan monitoring yang tepat, maksudnya yaitu memiliki perhitungan yang benar dan akurat, kemudian perencanaan cost harus berbanding lurus dengan progres proyek.

- Memastikan memiliki sumber daya manusia (SDM) yang tepat dan berkualitas dalam melakukan pengendalian biaya proyek sesuai dengan schedule proyek 


\begin{tabular}{|c|c|c|}
\hline & Variabel Risiko & Kontrol/ Pencegahan Risiko \\
\hline $\mathbf{X} 23$ & $\begin{array}{l}\text { Kualitas bekisting (formwork) } \\
\text { yang buruk }\end{array}$ & $\begin{array}{l}\text { - Melakukan kajian baik terhadap sistem, metode kerja dan pengadaan } \\
\text { yang tepat terhadap penggunaan bekisting yang baik } \\
\text { - Melakukan monitoring atau pengawasan yang baik terhadap perawatan } \\
\text { bekisting }\end{array}$ \\
\hline X50 & $\begin{array}{l}\text { Kurangnya pendanaan untuk } \\
\text { proyek }\end{array}$ & $\begin{array}{l}\text { - Harus melakukan perencanaan arus kas (planning cash flow) yang tepat } \\
\text { yang di dalamnya terdapat progress fisik dan perencanaan cost dan } \\
\text { revenue. }\end{array}$ \\
\hline $\mathbf{X 5 0}$ & $\begin{array}{l}\text { Kurangnya pendanaan untuk } \\
\text { proyek }\end{array}$ & $\begin{array}{l}\text { - Melakukan pemantauan arus kas (monitoring cash flow) dengan rutin } \\
\text { - Kontraktor harus memiliki bank financing backup atau uang cadangan } \\
\text { darimanapun untuk mengantisipasi risiko kurangnya pendanaan } \\
\text { - Kontraktor berhak memberikan somasi kepada owner dan dapat } \\
\text { memutuskan kontrak kerja apabila sudah tidak menguntungkan sama } \\
\text { sekali }\end{array}$ \\
\hline X37 & $\begin{array}{l}\text { Kurangnya kemampuan/ skill } \\
\text { tenaga kerja dari pihak } \\
\text { subkontraktor }\end{array}$ & $\begin{array}{l}\text { - Melakukan pengawasan dan seleksi terhadap kemampuan tenaga kerja } \\
\text { subkontraktor pada saat prakualifikasi subkontraktor. }\end{array}$ \\
\hline X8 & $\begin{array}{l}\text { Terjadi material yang terjatuh } \\
\text { dari ketinggian }\end{array}$ & $\begin{array}{l}\text { - Membuat rencana penempatan barang yang layak di dalam metode } \\
\text { kerja. } \\
\text { - Memberikan safety induction kepada pekerja setiap hari sebelum } \\
\text { memulai pekerjaan untuk membahas terkait target pekerjaan pada hari } \\
\text { tersebut dan mengingatkan risiko apa saja yang terdapat dalam } \\
\text { pekerjaan tersebut dan pentingnya akan keselamatan kerja dengan } \\
\text { menggunakan perangkat keselamatan alat pelindung diri (APD) } \\
\text { - Melakukan inspeksi keselamatan rutin pada setiap area pekerjaan yang } \\
\text { berlangsung oleh tim SHE }\end{array}$ \\
\hline $\mathrm{X} 26$ & $\begin{array}{l}\text { Terjadinya checklist berulang } \\
\text { kali }\end{array}$ & $\begin{array}{l}\text { - Melakukan pengecekan terhadap kualitas pekerjaan secara internal } \\
\text { melalui tim supervisi } \\
\text { - Melakukan kontrol terhadap urutan aliran pekerjaan yang seharusnya. } \\
\text { - Meningkatkan performa kualitas terhadap supervisi dan tenaga kerja, } \\
\text { caranya adalah dengan memberikan pelatihan-pelatihan dan berbagi } \\
\text { pengetahuan (sharing knowledge) antara sesame rekan tim. } \\
\text { - Melakukan kesepakatan standar pencapaian kualitas sehingga } \\
\text { pengecekan (checklist) lebih terukur }\end{array}$ \\
\hline $\mathbf{X 1 7}$ & $\begin{array}{l}\text { Perencanaan atau planning } \\
\text { kebutuhan material yang tidak } \\
\text { tepat }\end{array}$ & $\begin{array}{l}\text { - Membuat program perencanaan material (material planning) sebagai } \\
\text { turunan dari perencanaan progress (progress planning) atau master } \\
\text { schedule dengan menghitung dan memproyeksikan kebutuhan material } \\
\text { secara tepat } \\
\text { - Memberikan pelatihan kepada sumber daya manusianya (SDM) dalam } \\
\text { membuat perencanaan kebutuhan material yang tepat. }\end{array}$ \\
\hline X16 & $\begin{array}{l}\text { Pemakaian dan permintaan } \\
\text { material yang berlebihan }\end{array}$ & $\begin{array}{l}\text { - Menghitung kebutuhan material sesuai dengan kebutuhan progress fisik } \\
\text { yang diharapkan } \\
\text { - Membuat metode kerja tepat } \\
\text { - Supervisi harus memonitor antara kebutuhan dan pemakaian material } \\
\text { - Rutin dalam melakukan pengecekan dan control terhadap perhitungan } \\
\text { QS terhadap kebutuhan material. }\end{array}$ \\
\hline
\end{tabular}




\begin{tabular}{|c|c|c|}
\hline & Variabel Risiko & Kontrol/ Pencegahan Risiko \\
\hline $\mathbf{X} 2$ & $\begin{array}{l}\text { Pekerjaan tidak dilakukan } \\
\text { sesuai prosedur K3 yang } \\
\text { ditetapkan }\end{array}$ & $\begin{array}{l}\text { - Pembuatan dan melakukan sosialisasi JSA sebelum pekerjaan dimulai } \\
\text { dengan tenaga kerja, supervisi, tim safety dan manager lapangan setiap } \\
\text { harinya. }\end{array}$ \\
\hline X35 & $\begin{array}{l}\text { Kurangnya produktivitas } \\
\text { lapangan dari subkontraktor }\end{array}$ & $\begin{array}{l}\text { - Pada saat prakualifikasi tender subkontraktor harus tepat sesuai dengan } \\
\text { kebutuhan proyek tersebut, baik dari segi kualitas, kapasitas, spesialisasi } \\
\text { dari subkontraktor tersebut. }\end{array}$ \\
\hline X9 & $\begin{array}{l}\text { Kecelakaan kerja akibat } \\
\text { pekerja jatuh dari ketinggian }\end{array}$ & $\begin{array}{l}\text { - Memberikan induksi keamanan (safety induction) kepada para pekerja } \\
\text { sebelum memulai pekerjaan setiap pagi hari } \\
\text { - Memberikan pelindung pada sisi bangunan dengan layak. } \\
\text { - Melakukan inspeksi keselamatan rutin pada setiap area pekerjaan yang } \\
\text { berlangsung } \\
\text { - Menggunakan metode dan teknik konstruksi yang aman }\end{array}$ \\
\hline X14 & $\begin{array}{l}\text { Terjadinya fatality di lokasi } \\
\text { proyek }\end{array}$ & $\begin{array}{l}\text { - Pembuatan dan sosialisasi job safety analysis (JSA) sebelum pekerjaan } \\
\text { dimulai. } \\
\text { - Melakukan inspeksi keselamatan rutin (safety inspection) pada area } \\
\text { kerja, alat kerja dan kesehatan tenaga kerja sebelum memulai pekerjaan } \\
\text { (fatigue test) } \\
\text { - Memberikan induksi keamanan (safety induction) kepada para pekerja } \\
\text { sebelum memulai pekerjaan setiap pagi hari } \\
\text { - Menerapkan sistem keamanan yang sesuai dengan standar perusahaan } \\
\text { - Memberikan sanksi terhadap pekerjaan yang melanggar aturan } \\
\text { keamanan kerja perusahaan }\end{array}$ \\
\hline $\mathbf{X} 7$ & $\begin{array}{l}\text { Kecelakaan akibat robohnya } \\
\text { climbing formwork }\end{array}$ & $\begin{array}{l}\text { - Pembuatan dan sosialisasi job safety analysis (JSA) sebelum pekerjaan } \\
\text { dimulai. } \\
\text { - Melakukan inspeksi keselamatan (safety inpection) rutin pada area } \\
\text { kerja, alat kerja dan kesehatan tenaga kerja sebelum memulai pekerjaan } \\
\text { (fatigue test) } \\
\text { - Membuat metode kerja yang tepat sesuai dengan sistem yang digunakan } \\
\text { - Melakukan pengawasan rutin dan memastikan bahwa tim konstruksi } \\
\text { melakukan pekerjaan sesuai dengan urutan dalam metode sistem kerja } \\
\text { yang digunakan } \\
\text { - Menggunakan alat-alat kerja yang telah diberikan tanda aman digunakan } \\
\text { (safety tagging) oleh tim SHE }\end{array}$ \\
\hline
\end{tabular}

Menurut Indah (2017) bahwa tingginya angka kecelakaan di bidang konstruksi bukan disebabkan oleh tingkat kesadaran yang rendah tentang K3 namun lebih berkaitan dengan kurangnya penerapan program dan sistem K3. Oleh sebab itu, berdasarkan hasil yang didapatkan pada tabel 5 di atas bahwa betapa pentingnya pemahaman akan metode kerja yang akan digunakan dan tingkat kualitas dari sumber daya manusianya baik dalam segi ketrampilan bekerja maupun pengetahuan akan keselamatan kerja dalam pelaksanaan pembangunan gedung bertingkat tinggi. 


\section{KESIMPULAN DAN SARAN}

\section{Kesimpulan :}

a. Dari 64 variabel risiko yang ada, 21 variabel risiko di antaranya merupakan termasuk ke dalam kategori risiko dominan (high risk) yang berpengaruh pada kinerja pelaksanaan proyek pembangunan gedung bertingkat tinggi.

b. Berdasarkan hasil analisa penelitian bahwa variabel risiko perubahan desain dari owner merupakan risiko yang paling dominan dan masih menjadi permasalahan utama yang sering dihadapi dan memiliki dampak pengaruh yang sangat signifikan terhadap progress pelaksanaan proyek.

c. Berdasarkan hasil analisa penelitian didapatkan bahwa terdapat beberapa faktor penyebab utama yang berpengaruh terhadap variabel-variabel risiko dominan antara lain:

- Faktor dari kualitas sumber daya manusia (SDM) yang rendah

- Faktor pemilihan metode kerja yang digunakan kurang tepat

- Faktor dari pengguna jasa atau owner

- Faktor terhadap ketersediaan sumber daya material, kelayakan alat atau equipment dan perangkat pendukung kerja yang belum memadai

d. Terdapat beberapa rekomendasi yang dihasilkan dari penelitian ini yaitu:

- Pemimpin proyek harus lebih memperhatikan kualitas dan kebutuhan dari sumber daya manusianya dengan memberikan pelatihan dan sertifikasi demi meningkatkan kualitasnya terutama dalam hal kesehatan dan keselamatan kerja (K3).

- Pada saat masa tender proyek, perlu adanya evaluasi dari pihak kontraktor untuk mengetahui latar belakang owner yang memberikan tender proyek tersebut terutama dalam hal kondisi keuangannya atau bagaimana proses pembayarannya pada proyekproyek sebelumnya.

- Pada saat masa perencanaan konstruksi, perlu dipersiapkannya metode-metode kerja yang tepat, efisien secara biaya dan waktu dan aman digunakan oleh kontraktor.

- Pada saat masa tender proyek, perlu dilakukannya contract condition review oleh kontraktor untuk menganalisis risiko pada setiap klausul kontrak baru proyek tersebut. Hal ini berguna untuk memastikan klausul kontrak tersebut jelas dan tidak terdapat klausul kontrak yang dapat merugikan pihak kontraktor apabila kontraktor mendapatkan proyek tersebut, terutama terkait desain awal yang telah dibuat pada awal masa perencanaan konstruksi dan harus dicantumkan klausul kontrak khusus jika terjadi perubahan desain di masa depan sehingga tidak merugikan kedua belah pihak.

\section{Saran:}

a. Setiap pemimpin perusahaan konstruksi yang akan atau sedang terlibat dalam proyek pembangunan gedung bertingkat diharapkan untuk lebih memperhatikan secara khusus terhadap 21 variabel risiko dominan, sehingga proyek dapat berjalan dengan lancar dan selesai tepat waktu dan sesuai dengan anggaran.

b. Untuk penelitian selanjutnya disarankan dapat meneliti lebih dalam dan spesifik lagi terhadap risiko-risiko lain yang mempengaruhi proyek pembangunan gedung bertingkat tinggi baik di Ibukota Jakarta atau di kota yang lainnya. 


\section{REFERENSI}

Cortin, R. (2014). The Identification and Reduction of Risk in Project Management, p. 26.

Indah, A. (2017). Evaluasi Penerapan Keselamatan Dan Kesehatan Kerja (K3) Pada Proyek Bangunan Gedung Di Kabupaten Cirebon, Jurnal Teknik Sipil dan Perencanaan, 19 (1).

Project Management Institute (2013). A Guide to The Project Management Body of Knowledge (PMBOK Guide), Fifth edition, Project Management Institute, Inc, Newtown Square, Pennsylvania.

Project Management Institute (2017). A Guide to The Project Management Body of Knowledge (PMBOK Guide), Sixth edition, Project Management Institute, Inc, Newtown Square, Pennsylvania.

Saaty, T.L. and Tran, L.T. (2007). On The Invalidity of Fuzzifying Numerical Judgments In The Analytic Hierarchy Process", ISAHP, Chile.

Yuliana, C. and Hidayat, G. (2017). Manajemen Risiko Pada Proyek Gedung Bertingkat di Banjarmasin. Info Teknik, 18 (2), 255-270

Zhou, C., Wang, B. and Guo, Y. (2014). An Innovative Application of AHP and Value Engineering Techniques in Project Management of High-Rise Buildings, ICCREM 2014, International Conference on Construction and Real Estate Management, American Society of Civil Engineers, Kunming, China. 